\title{
Study on the Differentially Expressed Genes and Signaling Pathways in Systemic Lupus Erythematosus Using Integrated Bioinformatics Method
}

\author{
Jing Liang \\ Shanghai Jiao Tong University School of Medicine \\ Xin Zhang \\ Tianjin Xiangyang hospital \\ Wenjia Zhao ( $\nabla$ wenjiazhao@aliyun.com ) \\ Shanxi Provincial Hospital of traditional Chinese Medicine
}

\section{Research Article}

Keywords: systemic lupus erythematosus, GEO data, key genes mining, pathogenesis mechanism.

Posted Date: December 29th, 2020

DOl: https://doi.org/10.21203/rs.3.rs-134050/v1

License: (c) (1) This work is licensed under a Creative Commons Attribution 4.0 International License. Read Full License 


\section{Abstract}

Background: Systemic lupus erythematosus (SLE) is a chronic immune connective tissue disease, which is common in women of childbearing age and easy to cause multiple organ inflammatory injury. The occurrence of prostate cancer is the result of multiple factors and genes, but we have little understanding of the mechanism involved. In this study, we deeply explored and analyzed the existing gene data in GEO database in order to find the key genes and new therapeutic targets of SLE.

Results: The expression profile dataset of GDS4185, GDS4888, GDS4889 and GDS4890 containing 99 specimens, 42 cases of SLE patients and 57 cases of normal volunteers, were downloaded from the Gene Expression Omnibus (GEO) website. The differentially expressed genes (DEGs) in different tissues was analyzed by statistical hypothesis $\mathrm{T}$ test. The gene ontology (GO) enrichment analysis was carried out by the DAVID online tool. KEGG pathway annotation of DEGs was carried out by the KOBAS online computing database. The protein-protein interaction (PPI) networks of the DEGs were built from the STRING website and Cytoscape software. A total of 839 DEGs were calculated from the four GEO datasets. The GO and KEGG analysis indicated that the functions of DEGs mostly participated in the Osteoclast differentiation, HTLV-I infection, Measles, FoxO signaling pathway, Herpes simplex infection, Primary immunodeficiency, Jak-STAT signaling pathway. The following 14 closely related genes, HERC5, TP53, CDC20, GNB2, GNB4, PPP2R1A, GNAI2, PMCH, SOCS3, HERC6, STAT1, SOCS1, ISG15, IFIT3, were key nodes from the PPI network. These genes may have synergistic or indirect interactions with each other in the process of biological metabolism inducing the pathogenesis of SLE.

Conclusion: Mining geo database has great scientific research value. In the future, scientific research must fully excavate a variety of database analysis methods. In this study, the screened candidate genes provide effective theoretical basis for the diagnosis, treatment, expected evaluation and related laboratory research of SLE, which are worthy of further experimental verification.

\section{Background}

Systemic lupus erythematosus (SLE) is a spontaneous autoimmune disease characterized by buccal butterfly rash, arthralgia, myalgia, and neuralgia, which can affect all organs and systems of the body ${ }^{[1]}$. Its basic pathological changes are vasculitis involving multiple organs and systems ${ }^{[2]}$. Serum autoantibodies and multiple systemic involvement are two main features of $\operatorname{SLE}^{[3]}$. This disease is predominant in women of childbearing age, mostly in the 15-64 age group, with an average incidence ratio of 1:9 for men and women ${ }^{[4]}$. Data show that the prevalence of SLE varies from (20-240)/100,000 to] $(1-10) / 100,000$ per year ${ }^{[5]}$. The pathogenesis of SLE is very complex. It is generally believed that the interaction of multiple genes and environmental factors leads to the continuous activation and apoptosis of $T$ and $B$ cells, and ultimately leads to excessive production of autoantibodies to damage their own tissues and organs ${ }^{[6]}$. To date the early diagnosis of SLE mainly relies on the clinical manifestations of patients and the detection of serum autoantibody markers, but the diagnosis of specificity and accuracy of this disease is not high. The treatment of SLE includes non-steroidal anti-inflammatory drugs, 
glucocorticoids, disease modifying anti-rheumatic drugs and novel biological targeting drugs ${ }^{[7]}$. Because of the deepening of basic research, the renewal of examination methods and the formation of international consensus, the level of diagnosis and treatment of SLE has been significantly improved, and the prognosis has also been significantly improved. However, in recent years, with the gradual increase of SLE combined with cardiovascular events, the mortality rate is gradually on the rise. Therefore, it is significant and urgent to find the potential pathogenic mechanism of SLE, to explore more available early diagnostic methods, more dependable pathogenic genes for monitoring relapse and disease control, and to investigate a more useful method to improve SLE symptoms. As an effective and up-to-date technology to obtain genetic information, gene expression datasets have been in common usage to integration gene expression profiles information and to explore molecular mechanism in a great deal of diseases. These microarrays offer a new approach for exploring pathogenic factors. It provides broad expects for drug-based target prediction and wide application of molecular therapy gene expression chips. There are a lot of studies in which profiles are uploaded on public database platform, also integration of these profiles may further explore pathogenesis of this disease.

At present, many literatures and papers have been carried out on SLE gene expression arrays ${ }^{[8-10]}$. These literatures and papers have explored a great deal of DEGs that may participate in the occurrence and development of SLE. But the results of identifying the prominently expressed mRNAs were not consistent. Because of the incidence of organization or sample in different experiment, distinct genetic testing datasets, various data treatment means and due to samples collection from dissimilar backgrounds, they are re-expressed in diverse studies. Therefore, there are still certain deficiencies in single cohort researches. These research data should be re-integrated. The consolidation and merging of microarray data from multiple gene expression profiles can puzzle the difficulties out and find important and significant molecular markers. Robust rank aggregation (RRA) method is specially designed for comparing multiple ranked gene lists ${ }^{[1]}$. RRA uses a probability model to aggregate, which has a strong tone and helps to calculate the saliency probability of all elements in ultimate position ${ }^{[12]}$. The RRA method suppresses the effect of outliers on the results, leaving only the genes associated with statistics $^{[13]}$. The $P$-value can delegate the hierarchical position and importance of a gene. RRA method is an effective comprehensive analysis method for identifying genes in statistical sense. In addition, this is useful when different technology platforms acquire different types of genes and do not have a complete mRNAs ranking.

In this research, we retrieved four microarray expression datasets, GDS4185 [14], GDS4888 ${ }^{[15]}, \mathrm{GDS} 4889^{[16]}$ and GDS4890 ${ }^{[17]}$, from the NCBI-Gene Expression Omnibus (GEO) database (https://www.ncbi.nlm.nih.gov/geo/). The CEL file of dataset is processed with R, and the expression value of log2 of single probe of each chip is generated with default parameters. Then, the $P$ value of each probe is obtained by two sample equal variance $T$ test and two sample heteroscedasticity $T$ test. In this study, $\mathrm{P}=0.05$ was defined as the differential expression threshold of gene or probe. David (the Database for Annotation $\varangle$ Visualization and Integrated Discovery) is a biological information database, which integrates biological data and analysis tools. It provides systematic and comprehensive biological 
function annotation information for large-scale gene or protein list, and helps users extract biological information from it. The enrichment analysis of gene ontology (GO) and KOBAS-Kyoto Encyclopedia of Genes and Genomes (KEGG) pathways of DEGs was carried out in David database. String database is a database to search for known protein-protein interactions and predict protein-protein interactions. We used STRING database to construct protein-protein interaction network (PPI), which is helpful to obtain the correlation of DEGs and discover the core regulatory genes of SLE. In summary, the gene fragments related to SLE occurrence and development were screened by SLE geographic database and analyzed comprehensively. The molecular mechanism and considerable signaling systems of these gene fragments were analyzed, and the interaction network of coding proteins was made. Our study produced results of causative factors for early prediction and judgment of SLE and provides effective drug targets for the remedy of SLE.

\section{Methods}

DNA microarray technology is a new technique for analyzing genomic profiles of gene expression. Various DNA microarrays and DNA chip equipments and systems have been exploited and commercialized. DNA microarray analysis consists of oligonucleotide chip, DNA chip and genome chip, which can be organized into two patterns: one is to repair object DNA on the carrier for analysis of a great deal of object DNA; the other is to repair many different probes on the carrier material for analysis of extensive different target DNA. The various probe sequences of the identical objective DNA were analyzed by $R$.

The gene expression profiles of GDS4185, GDS4888, GDS4889 and GDS4890 were screened using the keyword "lupus erythematosus" searched in the geographic dataset database (https://www.ncbi.nlm.nih.gov/geo/). GDS4185 is a GPL96 platform, [HG-U133A] Affymetrix Human Genome U133A Array, including 39 samples of normal human peripheral blood subsets and 28 SLE patients peripheral blood subsets. The platform of GDS4888 is GPL570, [HG-U133_Plus_2] Affymetrix Human Genome U133 Plus 2.0 Array, which contains 8 samples of normal human peripheral blood subsets and 6 SLE patients peripheral blood subsets. The platform of GDS4889 is GPL570, [HGU133_Plus_2] Affymetrix Human Genome U133 Plus 2.0 Array, which consists of 4 samples of normal human peripheral blood subsets and 4 SLE patients peripheral blood subsets. The platform of GDS4890 is GPL570, [HG-U133_Plus_2] Affymetrix Human Genome U133 Plus 2.0 Array, which contains 6 samples of normal human peripheral blood subsets and 4 SLE patients peripheral blood subsets. The platform and series matrix files are saved as TXT files. Software packages are used to process downloaded files and convert and reject substandard data. The data are classified, corrected and $\log _{2}$ converted.

\section{Screening for DEGs}

The downloaded DEGs platform and matrix file series are converted by using $\mathrm{R}$ language software and annotation package. The ID corresponding to probe name is transformed to the international canonical 
name of gene (gene symbol) and stored in TXT file. The DEGs analysis was carried out using limma software package in Bioconductor Package (available online: http://www.bioconductor.org/).

The correlative manipulating instruction codes were entered into R, and the DEGs in SLE and normal specimens of the four gene expression datasets were calculated by the limma software package.

Specimens with an adjusted $P$-value of $<0.05$ and log fold change $(F C)>2$ were treated as DEGs. The TXT outcomes were saved for later calculation.

\section{Integration of microarray data}

The list of DEGs from the four microarray datasets calculated by limma packet analysis was stored as a TXT file. The RRA software package was downloaded, and R was applied to run the command code. A portion of genes that were up- or down regulated in the four chips were saved for later research. The RRA approach is openly workable in the Comprehensive R Network (http://cran.r-project.org/).

\section{GO and KEGG pathway enrichment analyses of DEGs}

The DAVID database (https://david.ncifcrf.gov/) is a genetic database, which provides bioinformatic data and analysis tools, supplies systematic and complex bioinformatics annotations for extensive gene or protein datasets, and identifies the most significant bioinformatics annotations by statistical methods. The gene ontology (GO) enrichment analysis was carried out by the DAVID online tool. KEGG pathway annotation of DEGs was carried out by the KOBAS online computing database (http://kobas.cbi.pku.edu.cn/). In this research, we obtained the DEGs that were prominently up- and down-regulated as definitive factors from merged gene expression SLE data, and a P-value of $<0.05$ was treated different dramatically.

\section{PPI network integration}

The STRING database (http://string-db.org/) is an online database for searching for protein-protein interactions (PPIs), which helps to mine the core regulatory genes. It includes not only the direct physical interaction between proteins, but also the indirect functional correlation between proteins. Each node in the network graph represents a protein, and the lines between nodes represent the interaction between two proteins. All DEGs were input into STRING database to obtain PPIs, then imported into Cytoscape software to weighted, integrated, and calculated to obtain reliable value and build into a specific view. The corresponding proteins in the central node are probably key proteins or core genes to be screened with momentous pathogenic effect.

\section{Results}

\section{Microarray data information and identification of DEGs in SLE}

The SLE expression microarray datasets GDS4185, GDS4188, GDS4889 and GDS4890 were standardized, and the results are exhibited in Figure 1. When the GDS4185 dataset was analyzed by the 
limma package (corrected P-value $<0.05, \log F C>2$ ), 23 DEGs were received. Among them, 22 upregulated genes and 1 downregulated gene were identified. 333 DEGs were analyzed from the GDS4188 dataset, containing 221 upregulated genes and 122 downregulated genes. 579 DEGs were analyzed from the GDS4889 dataset, containing 357 upregulated genes and 222 downregulated genes. Additionally, 325 DEGs were analyzed from the GDS4890 dataset, containing 189 upregulated genes and 136 downregulated genes. The DEGs from the two specimen datasets contained in every microarray are exhibited in Figure 2. The cluster heatmaps of the top 20 DEGs are exhibited in Figure 3.

DEGS in SLE was identified by comprehensive bioinformatics. The microarray data of four kinds of SLE gene expression were analyzed by limma software package. The data were classified according to logarithmic variation, and then by RRA analysis was performed (corrected $P$ value $<0.05$ ). The RRA method assumes that each gene in each experiment is randomly arranged. If a gene ranks higher in all experiments, the smaller its $p$ value, the greater the possibility of differential gene expression. By rank analysis, we identified 839 DEGs, of which 289 were up-regulated and 550 were down-regulated. Using Rheatmap software, the Heatmap of Top 20 up-and down-regulated genes was drawn, as exhibited in Figure 3.

\section{GO term enrichment analysis of DEGs}

There are three categories in GO term enrichment analysis, which are biological process (BP), cellular component (CC) and molecular function (MF). They describe the MFs that gene products may perform, the CCs they are in, and the BPs they participate in. The results are showed in Figures 4 and 5. Significant enrichment results of the GO enrichment analysis are showed in Table 1. The BPs of DEGs mainly enriched in response to virus, type I interferon signaling pathway and cellular protein metabolic process. The main CCs concluded perinuclear region of cytoplasm, focal adhesion and cell-cell adherens junction. The MFs concluded protein binding, double-stranded RNA binding and actin filament binding.

\section{KEGG pathway analysis of DEGs}

Using the KOBAS online analysis database (http://kobas.cbi.pku.edu.cn/) to analyze the DEGs identified from SLE-integrated gene microarrays, the most obviously enriched pathways of the DEGs were submitted to KEGG database. The outcomes are exhibited in Table 2. The signaling pathways of DEGs were mainly enriched in the Osteoclast differentiation, HTLV-I infection, Measles, FoxO signaling pathway, Herpes simplex infection, Primary immunodeficiency and Jak-STAT signaling pathway in SLE. The differentially expressed genes and their attribute columns were introduced into Cytoscape to analysis the topological properties of each node in an interactive network.

\section{Analyzing DEGs in SLE using a PPI network}

The DEG expression products in SLE were analyzed by the STRING database (http://string-db.org) to build PPI networks, with a total of 839 DEGs, containing upregulated 289 genes and 550 downregulated 
genes. After deleting the isolated and partially linked nodes, a complete network of DEGs was built, as exhibited in Figure 6.

\section{Table $1 \mathrm{GO}$ analysis of DEGs associated with SLE}




\begin{tabular}{|c|c|c|c|c|}
\hline Category & ID & Term & adj_pval & Genes \\
\hline $\begin{array}{l}\text { Biological } \\
\text { Process }\end{array}$ & GO:0060337 & $\begin{array}{l}\text { type I interferon } \\
\text { signaling } \\
\text { pathway }\end{array}$ & 6.87E-09 & $\begin{array}{l}\text { IFIT3, IFI27, ISG15, OAS3, } \\
\text { RSAD2, XAF1, MX1, STAT1, } \\
\text { IFI6 }\end{array}$ \\
\hline $\begin{array}{l}\text { Cellular } \\
\text { CoMolecular } \\
\text { Functiononent }\end{array}$ & GO:0005634 & nucleus & $1.56 \mathrm{E}-07$ & $\begin{array}{l}\text { PDLIM7, MAF1, TGFB1, } \\
\text { ZKSCAN4, PKM, AKT1,'USP18, } \\
\text { MAZ, ZYX, MX1, BRD8, H1F0, } \\
\text { PPP2R1A, RBM42, ACTN4, } \\
\text { CIZ1, HERC6, HERC5, SLC3A2, } \\
\text { PKN1, RMI1, FLNA, NUCB1, } \\
\text { LAP3, G6PD, ARRB2, HSPB1, } \\
\text { CMIP, MAPK7, PTOV1, IFIH1, } \\
\text { NFKBID, TADA3, ZNF780A, } \\
\text { BANF1, MLF2, NR1H2, PFN1, } \\
\text { DRAP1, PIR, XAF1, BHLHE40, } \\
\text { MT1H, MAFF, MAP2K2, PTPA, } \\
\text { SPHK1, KLF16, S100A11, } \\
\text { NR4A1, MAFK, STAT1, LGALS9, } \\
\text { ZNF628, UBA1, MEX3C, DGKZ, } \\
\text { SH3BGRL3, ASNA1 }\end{array}$ \\
\hline $\begin{array}{l}\text { Biological } \\
\text { Process }\end{array}$ & G0:0009615 & $\begin{array}{l}\text { response to } \\
\text { virus }\end{array}$ & 4.99E-07 & $\begin{array}{l}\text { IFIT3, IFIH1, DDX60, OAS3, } \\
\text { HSPB1, RSAD2, IFI44, MX1, } \\
\text { BANF1 }\end{array}$ \\
\hline $\begin{array}{l}\text { Biological } \\
\text { Process }\end{array}$ & GO:0051607 & $\begin{array}{l}\text { defense } \\
\text { response to } \\
\text { virus }\end{array}$ & $1.08 \mathrm{E}-06$ & $\begin{array}{l}\text { IFIT3, ISG15, DDX60, OAS3, } \\
\text { HERC5, RSAD2, IFI44L, MX1, } \\
\text { STAT1, GBP1 }\end{array}$ \\
\hline $\begin{array}{l}\text { Molecular } \\
\text { Function }\end{array}$ & GO:0005515 & protein binding & 4.33E-06 & $\begin{array}{l}\text { PRR16, PDLIM7, RAB5C, } \\
\text { TGFB1, ZKSCAN4, SHKBP1, } \\
\text { PKM, AKT1, USP18, MAZ, } \\
\text { ISG15, CLCF1, RNF219, DDX60, } \\
\text { MLST8, ZYX, MX1, FMNL1, } \\
\text { H1F0, PPP2R1A, RBM42, } \\
\text { ACTN4, SOCS3, CIZ1, SLC3A2, } \\
\text { HERC5, PKN1, RMI1, JUNB, } \\
\text { FLNA, LRRC25, NUCB1, CD37, } \\
\text { G6PD, GNB2, ARRB2, CFL2, } \\
\text { HSPB1, CMIP, VAMP2, MAPK7, } \\
\text { EMP3, PPP1R15A, COPE, } \\
\text { GBP1, IFIH1, NFKBID, TADA3, } \\
\text { TNFRSF12A, USP5, OAS3, } \\
\text { RSAD2, STARD10, NAPA, } \\
\text { BANF1, MLF2, NR1H2, PFN1, } \\
\text { DRAP1, PIR, BHLHE40, MT11, } \\
\text { C9ORF16, MAP2K2, PTPA, } \\
\text { SPHK1, S100A11, NR4A1, } \\
\text { MAFK, STAT1, IFIT3, PPP1R9B, } \\
\text { APOL1, ZNF217, UBA1, } \\
\text { MEX3C, DGKZ, ASNA1, IFI6 }\end{array}$ \\
\hline $\begin{array}{l}\text { Cellular } \\
\text { CoMolecular } \\
\text { Functiononent }\end{array}$ & G0:0005737 & cytoplasm & 1.36E-05 & $\begin{array}{l}\text { PDLIM7, IFI44L, MAF1, TGFB1, } \\
\text { PKM, AKT1, DDX60, MCOLN1, } \\
\text { MLST8, ZYX, MX1, RBM42, } \\
\text { ACTN4, SOCS3, HERC6, } \\
\text { HERC5, SLC3A2, PKN1, IFI44, }\end{array}$ \\
\hline
\end{tabular}


PNPLA2, FLNA, LAP3, G6PD, ARRB2, HSPB1, CMIP, MAPK7, SPATS2L, PPP1R15A, UBE2S, OAS3, BANF1, MLF2, NR1H2,

PFN1, TPGS1, PIR, MT1H, MAP2K2, PTPA, GIMAP8, SPHK1, S100A11, NR4A1, STAT1, LGALS9, IFIT3, PPP1R9B, UBA1, MEX3C, DGKZ, SH3BGRL3, ASNA1

$\begin{array}{lll}\text { Cellular } & \text { G0:0005829 cytosol } & \text { MIDN, IFIH1, OAS3, NAPA, } \\ \text { CoMolecular } & \text { 1.92E-05 } & \text { STARD10, MAF1, BANF1, PKM, } \\ \text { Functiononent } & \text { AKT1, PFN1, USP18, ISG15, } \\ & \text { XAF1, MLST8, MX1, FMNL1, } \\ & \text { PPP2R1A, SOCS3, MAP2K2, } \\ & \text { GIMAP8, HERC6, SPHK1, } \\ & \text { HERC5, PKN1, PNPLA2, STAT1, } \\ & \text { FLNA, IFIT3, G6PD, GNB2, } \\ & \text { ARRB2, UBA1, HSPB1, MAPK7, } \\ & \text { VAMP2, TRAPPC1, PPP1R15A, } \\ & \text { COPE, GBP1 }\end{array}$

$\begin{array}{llll}\text { Molecular } & \text { G0:0051721 } & \begin{array}{l}\text { protein } \\ \text { phosphatase 2A } \\ \text { binding }\end{array} & \text { 6.31E-04 AKT1, PTPA, SPHK1, STAT1 }\end{array}$

\begin{tabular}{|c|c|c|c|c|}
\hline $\begin{array}{l}\text { Biological } \\
\text { Process }\end{array}$ & G0:0032515 & $\begin{array}{l}\text { negative } \\
\text { regulation of } \\
\text { phosphoprotein } \\
\text { phosphatase } \\
\text { activity }\end{array}$ & 8.27E-04 & PPP1R9B, PTPA, PPP1R15A \\
\hline
\end{tabular}

$\begin{array}{lll}\text { Biological } & \mathrm{GO} 00043154 & \text { negative } \\ \text { Process } & \text { regulation of } \\ & \text { cysteine-type } \\ & \text { endopeptidase } \\ & \text { activity involved } \\ \text { in apoptotic } \\ \text { process }\end{array}$

9.80E-04 AKT1, LAMP3, ARRB2, NR4A1, IFI6

$\begin{array}{lll}\text { Cellular } & G 0: 0048471 & \begin{array}{l}\text { perinuclear } \\ \text { region of } \\ \text { coMolecular }\end{array} \\ \text { Functiononent } & & \text { cytosm }\end{array}$

0.001140013

PTOV1, LAMP3, GNB2, ACTN4, MAP2K2, HERC5, VAMP2, MAF1, MX1, STAT1, MT1H, FLNA

$\begin{array}{lll}\text { Biological } & \text { GO:0045071 } & \text { negative } \\ \text { Process } & \text { regulation of } \\ & \text { viral genome } \\ & \text { replication }\end{array}$

Cellular GO:0005925 focal adhesion

0.002278891

LAP3, PFN1, GNB2, PDLIM7,

CoMolecular

Functiononent ACTN4, MAP2K2, HSPB1, ZYX, FLNA

Biological

Process
GO:1902176

negative regulation of oxidative stressinduced intrinsic 
apoptotic

signaling

pathway

$\begin{array}{llll}\text { Biological } & \text { G0:0032270 } & \begin{array}{l}\text { positive } \\ \text { regulation of } \\ \text { cellular protein } \\ \text { metabolic }\end{array} & 0.004001111 \quad \text { NR1H2, AKT1, TGFB1 } \\ \text { process } & & \\ & & \end{array}$

\begin{tabular}{|c|c|c|c|c|}
\hline $\begin{array}{l}\text { Biological } \\
\text { Process }\end{array}$ & Go:0043536 & $\begin{array}{l}\text { positive } \\
\text { regulation of } \\
\text { blood vessel } \\
\text { endothelial cell } \\
\text { migration }\end{array}$ & 0.006408858 & AKT1, HSPB1, TGFB1 \\
\hline
\end{tabular}

Molecular G0:0003725 double-stranded 0.006651476 IFIH1, DDX60, OAS3, SLC3A2

Function RNA binding

$\begin{array}{llll}\begin{array}{l}\text { Cellular } \\ \text { CoMolecular Go:0031982 vesicle }\end{array} & 0.007093041 & \begin{array}{l}\text { PKM, AKT1, LAMP3, GNB2, } \\ \text { VAMP2 }\end{array}\end{array}$

Functiononent

\begin{tabular}{|lllll|}
$\begin{array}{l}\text { Biological } \\
\text { Process }\end{array}$ & G0:0035924 & $\begin{array}{l}\text { cellular } \\
\text { response to } \\
\text { vascular } \\
\text { endothelial } \\
\text { growth factor } \\
\text { stimulus }\end{array}$ & 0.009326365 & AKT1, HSPB1, NR4A1 \\
\hline $\begin{array}{l}\text { Molecular } \\
\text { Function }\end{array}$ & G0:0051015 & $\begin{array}{l}\text { actin filament } \\
\text { binding }\end{array}$ & 0.009604694 & $\begin{array}{l}\text { FMNL1, PPP1R9B, ACTN4, } \\
\text { CFL2, FLNA }\end{array}$ \\
\hline $\begin{array}{l}\text { Cellular } \\
\text { CoMolecular }\end{array}$ & G0:0015629 & $\begin{array}{l}\text { actin } \\
\text { cytoskeleton }\end{array}$ & 0.009642609 & $\begin{array}{l}\text { H1F0, PPP1R9B, PDLIM7, } \\
\text { ACTN4, CFL2, FLNA }\end{array}$ \\
$\begin{array}{l}\text { Biological } \\
\text { Process }\end{array}$ & G0:0033138 & $\begin{array}{l}\text { positive } \\
\text { regulation of } \\
\text { peptidyl-serine } \\
\text { phosphorylation }\end{array}$ & 0.010108194 & $\begin{array}{l}\text { AKT1, ARRB2, PPP1R15A, } \\
\text { TGFB1 }\end{array}$ \\
\hline $\begin{array}{l}\text { Cellular } \\
\text { CoMolecular } \\
\text { Functiononent }\end{array}$ & G0:0005913 & $\begin{array}{l}\text { cell-cell } \\
\text { adherens } \\
\text { junction }\end{array}$ & 0.012526333 & $\begin{array}{l}\text { PKM, PFN1, SLC3A2, S100A11, } \\
\text { ZYX, STAT1, FLNA }\end{array}$ \\
\hline $\begin{array}{l}\text { Molecular } \\
\text { Function }\end{array}$ & G0:0019888 & $\begin{array}{l}\text { protein } \\
\text { phosphatase } \\
\text { regulator } \\
\text { activity }\end{array}$ & 0.014199861 & PPP2R1A, PTPA, PPP1R15A \\
\hline $\begin{array}{l}\text { Biological } \\
\text { Process }\end{array}$ & G0:0032480 & $\begin{array}{l}\text { negative } \\
\text { regulation of } \\
\text { typel interferon } \\
\text { production }\end{array}$ & 0.015578596 & IFIH1, ISG15, HERC5 \\
\hline
\end{tabular}

Abbreviation: DEGs, differentially expressed genes; GO, gene ontology. 
Table 2 KEGG pathway analysis of DEGs associated with SLE 


\begin{tabular}{|c|c|c|c|c|}
\hline Category & ID & Term & PValue & Genes \\
\hline KEGG_PATHWAY & hsa04380 & $\begin{array}{l}\text { Osteoclast } \\
\text { differentiation }\end{array}$ & 0.019071601 & $\begin{array}{l}\text { AKT1, SOCS3, SOCS1, } \\
\text { LILRA6, SPI1, NFKBIA, } \\
\text { NFKB2, STAT1, FOSL1, } \\
\text { TGFB1, JUNB }\end{array}$ \\
\hline KEGG_PATHWAY & hsa05166 & HTLV-I infection & 0.020203403 & $\begin{array}{l}\text { ZFP36, TLN1, CD3E, TP53, } \\
\text { SPI1, NFKBIA, CDC20, } \\
\text { NFKB2, ATM, TGFB1, AKT1, } \\
\text { CDKN1A, MAD2L1, CDKN2B, } \\
\text { IL2RG, JAK3, FOSL1 }\end{array}$ \\
\hline KEGG_PATHWAY & hsa05162 & Measles & 0.020974748 & $\begin{array}{l}\text { AKT1, IFIH1, CD3E, NFKBIB, } \\
\text { OAS3, TP53, NFKBIA, IL2RG, } \\
\text { JAK3, MX1, STAT1 }\end{array}$ \\
\hline KEGG_PATHWAY & hsa04068 & $\begin{array}{l}\text { FoxO signaling } \\
\text { pathway }\end{array}$ & 0.021976693 & $\begin{array}{l}\text { AKT1, GABARAPL1, } \\
\text { CDKN1A, PLK4, PLK3, SGK2, } \\
\text { S1PR1, CDKN2B, MAP2K2, } \\
\text { TGFB1, ATM }\end{array}$ \\
\hline KEGG_PATHWAY & hsa05168 & $\begin{array}{l}\text { Herpes simplex } \\
\text { infection }\end{array}$ & 0.031554476 & $\begin{array}{l}\text { HMGN1, MCRS1, IFIH1, } \\
\text { TAF5, SOCS3, NFKBIB, OAS3, } \\
\text { TP53, TNFSF14, NFKBIA, } \\
\text { STAT1, CD74, PPP1CA }\end{array}$ \\
\hline KEGG_PATHWAY & hsa05340 & $\begin{array}{l}\text { Primary } \\
\text { immunodeficiency }\end{array}$ & 0.032320365 & $\begin{array}{l}\text { CIITA, CD3E, IL2RG, CD4, } \\
\text { CD79A }\end{array}$ \\
\hline KEGG_PATHWAY & hsa04630 & $\begin{array}{l}\text { Jak-STAT } \\
\text { signaling pathway }\end{array}$ & 0.035396429 & $\begin{array}{l}\text { OSM, AKT1, IL23R, SOCS3, } \\
\text { SOCS1, CSF2RB, CSF3R, } \\
\text { IL2RG, IL5RA, JAK3, STAT1 }\end{array}$ \\
\hline KEGG_PATHWAY & hsa04010 & $\begin{array}{l}\text { MAPK signaling } \\
\text { pathway }\end{array}$ & 0.038059772 & $\begin{array}{l}\text { MAP2K2, DUSP10, TP53, } \\
\text { MAP4K2, NR4A1, NFKB2, } \\
\text { CACNA2D3, FLNA, TGFB1, } \\
\text { AKT1, DUSP2, ARRB2, } \\
\text { RASGRP4, MAP3K8, HSPB1, } \\
\text { MAPK7 }\end{array}$ \\
\hline KEGG_PATHWAY & hsa04151 & $\begin{array}{l}\text { PI3K-Akt signaling } \\
\text { pathway }\end{array}$ & 0.041489003 & $\begin{array}{l}\text { PPP2R1A, SGK2, MAP2K2, } \\
\text { EFNA1, PGF, MET, TP53, } \\
\text { NR4A1, PKN1, OSM, AKT1, } \\
\text { CDKN1A, ITGA6, GNB2, } \\
\text { COL6A3, CSF3R, IL2RG, } \\
\text { GNB4, JAK3, MLST8 }\end{array}$ \\
\hline KEGG_PATHWAY & hsa05145 & Toxoplasmosis & 0.043657689 & $\begin{array}{l}\text { CIITA, AKT1, ITGA6, GNAI2, } \\
\text { NFKBIB, SOCS1, NFKBIA, } \\
\text { STAT1, TGFB1 }\end{array}$ \\
\hline KEGG_PATHWAY & hsa05164 & Influenza A & 0.048173461 & $\begin{array}{l}\text { CIITA, AKT1, IFIH1, SOCS3, } \\
\text { MAP2K2, NFKBIB, OAS3, } \\
\text { NFKBIA, RSAD2, MX1, } \\
\text { STAT1, FURIN }\end{array}$ \\
\hline KEGG_PATHWAY & hsa05219 & Bladder cancer & 0.058216983 & $\begin{array}{l}\text { CDKN1A, TYMP, MAP2K2, } \\
\text { TP53, HBEGF }\end{array}$ \\
\hline
\end{tabular}




\begin{tabular}{|c|c|c|c|c|}
\hline KEGG_PATHWAY & hsa04722 & $\begin{array}{l}\text { Neurotrophin } \\
\text { signaling pathway }\end{array}$ & 0.066337545 & $\begin{array}{l}\text { AKT1, MAP2K2, NFKBIB, } \\
\text { TP53, SORT1, NFKBIA, BEX3, } \\
\text { MAPK7, ARHGDIA }\end{array}$ \\
\hline KEGG_PATHWAY & hsa04660 & $\begin{array}{l}\text { T cell receptor } \\
\text { signaling pathway }\end{array}$ & 0.067451619 & $\begin{array}{l}\text { AKT1, CD3E, MAP2K2, } \\
\text { NFKBIB, CD247, MAP3K8, } \\
\text { NFKBIA, CD4 }\end{array}$ \\
\hline KEGG_PATHWAY & hsa04062 & $\begin{array}{l}\text { Chemokine } \\
\text { signaling pathway }\end{array}$ & 0.070825899 & $\begin{array}{l}\text { AKT1, GNAI2, GNB2, ARRB2, } \\
\text { CXCL13, CCR1, NFKBIB, } \\
\text { NFKBIA, GNB4, JAK3, STAT1, } \\
\text { PXN }\end{array}$ \\
\hline KEGG_PATHWAY & hsa05132 & $\begin{array}{l}\text { Salmonella } \\
\text { infection }\end{array}$ & 0.077033696 & $\begin{array}{l}\text { PFN1, PLEKHM2, WASF1, } \\
\text { PKN1, TLR5, FLNA, RHOG }\end{array}$ \\
\hline KEGG_PATHWAY & hsa05321 & $\begin{array}{l}\text { Inflammatory } \\
\text { bowel disease } \\
\text { (IBD) }\end{array}$ & 0.078933302 & $\begin{array}{l}\text { IL23R, IL2RG, TLR5, STAT1, } \\
\text { FOXP3, TGFB1 }\end{array}$ \\
\hline KEGG_PATHWAY & hsa05230 & $\begin{array}{l}\text { Central carbon } \\
\text { metabolism in } \\
\text { cancer }\end{array}$ & 0.078933302 & $\begin{array}{l}\text { PKM, AKT1, G6PD, MAP2K2, } \\
\text { MET, TP53 }\end{array}$ \\
\hline KEGG_PATHWAY & hsa04350 & $\begin{array}{l}\text { TGF-beta } \\
\text { signaling pathway }\end{array}$ & 0.080600068 & $\begin{array}{l}\text { PPP2R1A, SMAD9, CDKN2B, } \\
\text { SMAD7, ID 1, SMAD 1, TGFB1 }\end{array}$ \\
\hline KEGG_PATHWAY & hsa04060 & $\begin{array}{l}\text { Cytokine-cytokine } \\
\text { receptor } \\
\text { interaction }\end{array}$ & 0.097158769 & $\begin{array}{l}\text { IL23R, TNFRSF12A, CCR1, } \\
\text { TNFSF14, TNFSF9, TGFB1, } \\
\text { OSM, RELT, CLCF1, CXCL13, } \\
\text { CSF2RB, CSF3R, IL2RG, } \\
\text { IL5RA }\end{array}$ \\
\hline
\end{tabular}

Abbreviations: DEGs, differentially expressed genes; KEGG, Kyoto Encyclopedia of Genes and Genomes.

\section{Discussion}

We built a PPI network of protein encoded by DEGs and screened out the following 14 genes that have distinct relation with SLE: HERC5, TP53, CDC20, GNB2, GNB4, PPP2R1A, GNAI2, PMCH, SOCS3, HERC6, STAT1, SOCS1, ISG15, IFIT3. The proteins expressed by these genes are critical nodes in the PPI network. Pathway enrichment analysis pointed out that the genes mostly participated in the Osteoclast differentiation, HTLV-I infection, Measles, FoxO signaling pathway, Herpes simplex infection, Primary immunodeficiency, Jak-STAT signaling pathway.

As E3 ubiquitin ligase, HERCS has classical ubiquitin ligase activity ${ }^{[18]}$. In addition, HERCS can bind ubiquitin-like protein molecule ISG15 to specific protein substrates ${ }^{[19]}$. Like the process of ubiquitination, ISG15 covalently binds to the target protein and modifies the target protein, which is called ISG localization ${ }^{[20]}$. Several studies have found that HERCS also play an important role in antiviral responses ${ }^{[21-22]}$. In terms of expression regulation, Perng et a ${ }^{[23]}$ found that HERCS gene expression is 
regulated by a variety of stimulation factors, especially inflammatory factors (such as LPS, TNF-a and IL $1 \beta)$.

Human TP53 gene is located at 17p13, about $20 \mathrm{~KB}$ in length, containing 11 exons, and transcript $2.8 \mathrm{~KB}$ mRNA, encoding protein $p 53^{[24]}$. As a transcription factor, $p 53$ induces the expression of downstream genes such as p21, BAX and GADD4 and plays an important role in cell apoptosis, cycle change, DNA repair, cell metabolism and autophagy ${ }^{[25]}$. Related studies have found that p53 gene polymorphism is associated with systemic lupus erythematosus susceptibility in Asian populations ${ }^{[26-27]}$. It has also been found that $\mathrm{p} 53$ induces the production of related proteins by binding to specific DNA sequences, thereby inhibiting the expression of DNA methyltransferase gene, thereby affecting DNA methylation level ${ }^{[28]}$. In addition, Shepherd et al ${ }^{[29]}$ found that the expression of TP53 gene in active SLE patients was higher than that in normal people, and linear regression analysis showed that the expression of TP53 gene was positively correlated with SLE-DAl. These results suggest that the abnormal expression of TP53 gene in peripheral blood T lymphocytes is related to the pathogenesis of SLE.

Cell division cycle molecule 20 (CDC20) is an important regulatory molecule at cell cycle checkpoint, which plays an important role in the regulation of cell mitotic anaphase by directly binding and activating the mitotic anaphase promoting complex ${ }^{[30]}$. APC/CDC20 complex has the activity of E3 ubiquitin ligase, and through the recognition of the structure domain of substrate degradation box, it performs the protein degradation mediated by ubiquitin cage haberasome ${ }^{[31]}$. Its abnormal expression can cause normal cells to produce non-integer ploidy by destroying cell mitosis, and then promote malignant transformation of cells $^{[32]}$. TP53 negatively regulates the expression of $C D C 20$, which is supported by evidence that the overexpression of TP53 inhibits the expression of CDC20, while the absence of TP53 leads to the expression of $\mathrm{CDC} 20^{[33]}$.

GNB2 is a house-keeping gene that codes for RACK1 protein in normal cells ${ }^{[34]}$. RACK1 protein as an important protein skeleton, intracellular protein joint, anchored proteins, involved in compound generated signaling molecule in cells, affect the active molecule subcellular localization, communication and the connection between the different signaling pathways, so as to exert its for signal transduction, gene expression, cell proliferation, differentiation and so on various aspects of adjustment, so the researchers widely believe that GNB2 participated in many important physiological processes and organisms as an important role in it ${ }^{[35-36]}$. When cells are stimulated, genes can respond quickly, encode synthetic proteins, realize transcriptional regulation and post-transcriptional level regulation of genes, and further trigger a series of delayed responses ${ }^{[37]}$. Nielsen et al ${ }^{[38]}$ knocked out the RACK1 gene in mice and found that the immune response to LPS or Poly I: $\mathrm{C}$ stimulation in mice was enhanced, which showed increased mortality. It has been preliminarily proved that RACK1 can inhibit overstrung innate immune response in mice ${ }^{[39]}$. In addition to RACK 1, CD8T cells and CD4T cells, Bolger et al ${ }^{[40]}$ also showed a certain degree of reduction in mouse $T$ cells. Li et al ${ }^{[41]}$ have found that RACK1 is associated with endocrine disruptors, suggesting that GNB2 is a bridge between the endocrine and immune systems. 
GNB4 gene is used to make $G$ protein 4 subunit (Gß4), which is one of the core members of $G$ protein signal transduction system ${ }^{[42]}$. G $\beta 4$ related signaling systems play an important role in the functioning of peripheral nerves ${ }^{[43]}$. GNB4 gene mutation can cause $\mathrm{G} \beta 4$-related $\mathrm{G}$ protein signaling pathway to be blocked, resulting in muscle atrophy, weakness and decreased tendon response ${ }^{[44]}$. Lohmann et al ${ }^{[45]}$ found that GNB4 gene mutation was associated with infectious motor neuropathy.

PP2A is a heterotrimeric holoenzyme complex and an important positive regulator of cell growth and proliferation ${ }^{[46]}$. As the structural subunit of protein phosphatase PP2A, PPP2R1A protein plays a role of scaffold and linkage in the whole enzyme catalysis process of PP2A and regulates the dephosphorylation process of PP2A substrate protein serine/threonine residues ${ }^{[47]}$. Some studies have found that the transcription and expression of PPP2R1A can affect the activity of the NF-KB pathway, thereby regulating environmental factors and mediating cell function ${ }^{[48]}$.

G protein a inhibitor 2(GNAI2) is an inhibitory G protein, which can inhibit adenylate cyclase and reduce the content of the second messenger (CAMP) in cells, thus resulting in the corresponding biological reaction ${ }^{[49]}$. Supper et al ${ }^{[50]}$ found that GNAI2 is involved in the regulation of intercellular connections and can regulate the functions related to glutamate signaling pathway and the functions related to mTOR signaling pathway.

Pro-melanin-concentrating hormone $(\mathrm{PMCH})$ is a key regulator in the body's energy homeostasis system, which is related to the occurrence of obesity ${ }^{[51]}$. Ferreira et al ${ }^{[52]}$ found that $\mathrm{PMCH}$ is related to body weight and energy consumption and plays a key role in maintaining the overall homeostasis of hypothalamus and neuroendocrine responses.

SOCS3 is one of the most active members of the SOCS family and the most important inhibitor of the JAK kinase and STAT signaling pathway ${ }^{[53]}$. It negatively regulates the expression of the JAK/STAT signaling pathway and its downstream target genes to prevent malignant cell transformation and

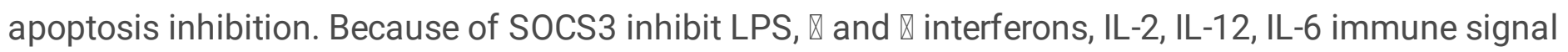
transduction related molecules, such as the body's natural immune response and the adaptive immune response has an important influence, closely associated with inflammatory disease development ${ }^{[54]}$. These studies suggest that the molecule SOCS3 may be a new target for the development of drugs for the treatment of SLE.

HERC6 is one of the E3 ligases of ISG15 ${ }^{[55]}$. The expression of ISG15 is closely related to interferon, suggesting that it plays an important role in immunity. Recombinant ISG15 can stimulate the proliferation of natural killer cells (NK) and enhance the cytotoxic effect of NK cells. In this process, $\mathrm{CD}^{+}{ }^{+} \mathrm{T}$ cells are necessary for ISG15-induced proliferation and cytotoxic effect of NK cells ${ }^{[56]}$.

Signal transduction and transcription activators (STAT) are a family of transcription factors involved in cell signal transduction. STAT1, an important member of the STATs protein family, plays an important regulatory role in cell growth, differentiation, proliferation and apoptosis mainly through Janus 
associated kinase-STAT signal pathway ${ }^{[57]}$. Weng et a ${ }^{[58]}$ used anti-stat1 antibody and immunohistochemical techniques in renal biopsy of 15 patients with diffuse proliferative lupus nephritis and found that the expression of STAT1 in renal tissue was high, and the prognosis of the disease was poor with high expression of STAT1. Kohanbash et al ${ }^{[59]}$ found that the renal tissues of MRL/ LPR mice with lupus nephritis were highly expressed with STAT1 and activated phosphorylated STAT1 could be detected in glomerular cells, while the negative regulators of JAK/STAT SOCS1 and SOCS3 were also significantly increased. STAT1 phosphorylation was induced by adding IFN- $\alpha$ or IFN- $\gamma$ to cultured MRL/ LPR mouse mesangial cells. Chen et al ${ }^{[60]}$ found in the rat model of lupus that calcium-dependent kinase can inhibit STAT1-mediated IFN- signal transduction. Therefore, some scholars speculate that reducing the expression of STAT1 may reduce the effect of IFN and become a potential therapy for SLE.

As one of the important negative feedback factor types of the JAK/STAT pathway, SOCS1 and the other two negatively regulated protein families are protein tyrosine phosphate and STAT activation inhibitor proteins, which play a crucial role in the development of IL-10 mediators in SLE patients ${ }^{[61]}$. SOCS1 can induce the degradation of NF-KB and inhibit the activity of NF-KB. Meanwhile, SOCS1 is involved in innate immunity and plays an important role in the pathogenesis of inflammatory diseases. SOCS1 also plays a crucial role in systemic autoimmune suppression ${ }^{[62]}$.

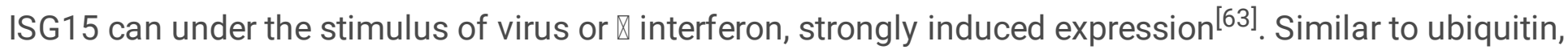
ISG15 can to covalent modification of proteins, but not mediated protein degradation. ISG15 is mainly involved in the body's innate immune function in the process of regulation and interferon ${ }^{[64]}$. Bianco et $\mathrm{al}^{[65]}$ found that the expression level of ISG15 mRNA in PBMCs of SLE patients was significantly positively correlated with SLE disease activity score index score and anti-double-stranded DNA antibody, and significantly negatively correlated with complement C3 and C4. The expression level of ISG15 mRNA in patients with active SLE is significantly higher than that in normal people and in disease remission, suggesting that the expression of ISG15 may be involved in the pathogenesis of SLE and significantly correlated with the activity of the disease ${ }^{[66]}$.

IFIT3 is a member of the related protein family encoded by interferon inducible gene and plays an important role in inhibiting virus and cell proliferation ${ }^{[67]}$. Wang et a ${ }^{[68]}$ found that IFIT3 mRNA in SLE group was significantly higher than that in non-SLE control group and normal control group, and IFIT3 mRNA in SLE active group was significantly higher than that in SLE inactive group. There was a very significant positive correlation between IFIT3 mRNA and SLEDAI score in SLE group. It suggests that the increase of the quantitative expression level of IFIT3 mRNA is of certain significance for the diagnosis of SLE patients, as well as the judgment of the disease activity and severity of SLE patients.

\section{Conclusions}

In this study, we deeply explored and analyzed the existing gene data of GEO database to find the key genes and new therapeutic targets of SLE. According to the standard process, the chip data in GEO 
database were collected, processed and integrated. The chip data were normalized and corrected. The results were analyzed by $\mathrm{R}$ language program.

A total of 839 differentially expressed genes were detected, including 289 up-regulated genes and 550 down-regulated genes. The range of candidate genes was further narrowed by heat map and volcano map analysis, and the differentially expressed genes, pathways and their encoded proteins were analyzed by go enrichment, KEGG pathway analysis and string online tools. The results showed that the differentially expressed proteins and their encoded genes were mainly concentrated in 14 genes: HERC5, TP53, CDC20, GNB2, GNB4, PPP2R1A, GNAI2, PMCH, SOCS3, HERC6, STAT1, SOCS1, ISG15, IFIT3.

Although our study provides some differentially expressed genes, the occurrence and development of SLE is a complex and multifactorial common outcome. The genes involved in the study may only be a part of them, or even a part of the secondary changes after the occurrence of SLE. It is necessary to continue to carry out in vitro and in vivo experimental verification in order to provide effective theoretical basis for the diagnosis, treatment, expected evaluation and related laboratory research of SLE. As a chip screening with large sample size, low cost and simple analysis, GEO database analysis can provide reference and basis for more people to carry out large-scale genomics research and follow-up research based on genomics through various statistical analysis methods.

\section{List Of Abbreviations}

SLE: Systemic lupus erythematosus; GEO: Gene Expression Omnibus; DEGs: differentially expressed genes; GO: gene ontology; KEGG: Kyoto Encyclopedia of Genes and Genomes; DAVID: the database for annotation, visualization and integrated discovery; KOBAS: KEGG orthology based annotation system; PPI: protein-protein interaction; RRA: Robust rank aggregation.

\section{Declarations}

\section{Availability of Data and Materials}

All data generated or analysed during this study are included in this published article.

\section{Ethics approval and consent to participate}

Not applicable.

\section{Consent for Publication}

Not applicable.

\section{Competing interests}

The authors declare that they have no competing interests. 


\section{Authors' contributions}

All authors contributed equally to this work.

\section{Acknowledgements}

Not applicable.

\section{References}

1. Andreoli L, Bertsias G K, Agmon-Levin N, et al. EULAR recommendations for women's health and the management of family planning, assisted reproduction, pregnancy and menopause in patients with systemic lupus erythematosus and/or antiphospholipid syndrome. Rheum. Dis. 2017; 76(3):476-485.

2. Stohl W, Schwarting A, Okada M, et al. Efficacy and Safety of Subcutaneous Belimumab in Systemic Lupus Erythematosus: A Fifty-Two-Week Randomized, Double-Blind, Placebo-Controlled Study. Arthritis Rheumatol. 2017; 69(5):1016-1027.

3. Chen L, Morris D L, Vyse T J. Genetic advances in systemic lupus erythematosus: an update. Opin. Rheumatol. 2017; 29(5):423-433.

4. Szabó M Z, Szodoray P, Kiss E. Dyslipidemia in systemic lupus erythematosus. Res. 2017; 65(2):1-8.

5. Van V R, Voskuyl A, Bertsias G, et al. A framework for remission in SLE: consensus findings from a large international task force on definitions of remission in SLE (DORIS). Rheum. Dis. 2017; 76(3):554-561.

6. Rubtsova K, Rubtsov A V, Thurman J M, et al. B cells expressing the transcription factor T-bet drive lupus-like autoimmunity. Clin. Invest. 2017; 127(4):1392.

7. Williams E M, Egede L, Faith T, et al. Effective Self-Management Interventions for Patients With Lupus: Potential Impact of Peer Mentoring. J. Med. Sci. 2017; 353(6):580.

8. Fasano S, Pierro L, Pantano I, et al. Longterm Hydroxychloroquine Therapy and Low-dose Aspirin May Have an Additive Effectiveness in the Primary Prevention of Cardiovascular Events in Patients with Systemic Lupus Erythematosus. Rheumatol. 2017; 44(7):1032.

9. Sciascia S, Radin M, Yazdany J, et al. Expanding the therapeutic options for renal involvement in lupus: eculizumab, available evidence. Int. 2017; 37(8):1249-1255.

10. Marinho A, Carvalho C, Boleixa D, et al. Vitamin D supplementation effects on FoxP3 expression in T cells and FoxP3 + /IL-17A ratio and clinical course in systemic lupus erythematosus patients: a study in a Portuguese cohort. Res. 2017; 65(1):197-206.

11. Feng Z, Hassan A E, Mcintosh S, et al. The Use of Summation to Aggregate Software Metrics Hinders the Performance of Defect Prediction Models. IEEE Trans. Softw. Eng. 2017; 43(5):476-491.

12. Yi Y, Lu X, Dekkers S, et al. Aggregation State of Metal-Based Nanomaterials at the Pulmonary Surfactant Film Determines Biophysical Inhibition. Sci. Technol. 2018; 52(15):8920-8929. 
13. Smeets $\mathrm{S}$, Wan W. Serial electron crystallography: merging diffraction data through rank aggregation. Appl. Crystallogr. 2017; 50(3):885-892.

14. Becker A M, Dao K H, Kwanghoon H B, et al. SLE Peripheral Blood B Cell, T Cell and Myeloid Cell Transcriptomes Display Unique Profiles and Each Subset Contributes to the Interferon Signature. PLoS One. 2013; 8(6): e67003.

15. Chieko K, Biljana S, Grün Joachim R, et al. Cell-Specific Type I IFN Signatures in Autoimmunity and Viral Infection: What Makes the Difference? PLoS One. 2013; 8(12): e83776.

16. Klippel J H, Karsh J, Stahl N I, et al. A controlled study of pneumococcal polysaccharide vaccine in systemic lupus erythematosus. Arthritis Rheumatol. 2010; 22(12):1321-1325.

17. Menssen A, Edinger G, Joachim R Grün, et al. SiPaGene: A new repository for instant online retrieval, sharing and meta-analyses of GeneChip expression data. BMC Genomics. 2009; 10(1):98.

18. Ritchie K J, Chang S H, Kim K I, et al. Role of ISG15 protease UBP43 (USP18) in innate immunity to viral infection. Med. 2017; 10(12):1374-1378.

19. Crespi R, Capparè $P$, Gherlone E. Magnesium-enriched hydroxyapatite compared to calcium sulfate in the healing of human extraction sockets: radiographic and histomorphometric evaluation at 3 months. Periodont. 2017; 80(2):210-8.

20. Reynolds C S, Ward M J, Fabian A C, et al. A multiwavelength study of the Seyfert 1 galaxy MCG-630-15. Not. Roy. Astron. Soc. 2018, 291(3):403-417.

21. Basters A, Geurink P P, Röcker A, et al. Structural basis for the specificity of USP18 towards ISG15. Struct. Mol. Biol. 2017; 24(3):270-278.

22. Zhou M J, Chen F Z, Chen H C, et al. ISG15 inhibits cancer cell growth and promotes apoptosis. J. Mol. Med. 2017; 39(2):446.

23. Perng Y C, Lenschow D J. ISG15 in antiviral immunity and beyond. Rev. Microbiol. 2018; 16(7):1.

24. Chang C K, Zhao Y S, Xu F, et al. TP53 mutations predict decitabine-induced complete responses in patients with myelodysplastic syndromes. J. Haematol. 2017; 176(4):600.

25. Canale M, Petracci E, Delmonte A, et al. Impact of TP53 Mutations on Outcome in EGFR-Mutated Patients Treated with First-Line Tyrosine Kinase Inhibitors. Cancer Res. 2017; 23(9):2195-2202.

26. Stengel A, Kern W, Haferlach T, et al. The impact of TP53 mutations and TP53 deletions on survival varies between AML, ALL, MDS and CLL: an analysis of 3307 cases. 2017; 31(3):705-711.

27. Kuo W T, Tu D G, Chiu L Y, et al. High pemetrexed sensitivity of docetaxel-resistant A549 cells is mediated by TP53 status and downregulated thymidylate synthase. Rep. 2017; 38(5):2787-2795.

28. Hayashi $\mathrm{H}$, Kohno $\mathrm{T}$, Ueno $\mathrm{H}$, et al. Utility of Assessing the Number of Mutated KRAS, CDKN2A, TP53, and SMAD4 Genes Using a Targeted Deep Sequencing Assay as a Prognostic Biomarker for Pancreatic Cancer. 2017; 46(3):335.

29. Shepherd F A, Lacas B, Le T G, et al. Pooled Analysis of the Prognostic and Predictive Effects of TP53 Comutation Status Combined With KRAS or EGFR Mutation in Early-Stage Resected NonSmall-Cell Lung Cancer in Four Trials of Adjuvant Chemotherapy. Clin. Oncol. 2017; 35(18):2018. 
30. Morriswood B, Engstler M. Let's get fISSical: fast in silico synchronization as a new tool for cell division cycle analysis. Parasitology. 2017; 145(2):1-14.

31. Krall A S, Christofk H R. Cell cycle: Division enzyme regulates metabolism. 2017; 546(7658):357-358.

32. Coller H A, Desai A. Cell cycle, cell division, and cell death. Biol. Cell. 2017; 28(6):693.

33. Meitinger F, Pereira G. The septin-associated kinase Gin4 recruits Gps1 to the site of cell division. Biol. Cell. 2017; 28(7):883.

34. Stallmeyer B, KuãŸ J, Kotthoff S, et al. A Mutation in the G-Protein Gene GNB2 Causes Familial Sinus Node and Atrioventricular Conduction Dysfunction. Res. 2017; 120(10):e33.

35. Alexander N, Sullivan K, Shaikh F, et al. Characteristics and management of ganglioneuroma and ganglioneuroblastoma-intermixed in children and adolescents. Blood Cancer. 2018; 65(1):e26964.

36. Oriol I, Sabé N, Simonetti A F, et al. Changing trends in the aetiology, treatment and outcomes of bloodstream infection occurring in the first year after solid organ transplantation: a single-centre prospective cohort study. Int. 2017; 30(9):903.

37. Liu H, Fei C N, Zhang Y, et al. Presence, distribution and molecular epidemiology of multi-drugresistant Gram-negative bacilli from medical personnel of intensive care units in Tianjin, China, 20072015. Hosp. Infect. 2017; 96(2):101-110.

38. Nielsen M H, Flygaard R K, Jenner L B. Structural analysis of ribosomal RACK1 and its role in translational control. Signal. 2017; 35:272-281.

39. Russo A, Scardigli R, La F R, et al. Increased cytoplasmic TDP-43 reduces global protein synthesis by interacting with RACK1 on polyribosomes. Mol. Genet. 2017; 26(8):1407-1418.

40. Bolger $\mathrm{G} B$. The RNA-binding protein SERBP1 interacts selectively with the signaling protein RACK1. Signal. 2017; 35:256-263.

41. Li D H, Chen F J, Li H Y, et al. The Soybean GmRACK1 Gene Plays a Role in Drought Tolerance at Vegetative Stages. J. Plant Physiol. 2018; 65(4):541-552.

42. Chang $Y T$, Coombs G, Ling T, et al. Epidemiology and trends in the antibiotic susceptibilities of Gram-negative bacilli isolated from patients with intra-abdominal infections in the Asia-Pacific region, 2010-2013. J. Antimicrob. Agents. 2017; 49(6):734.

43. Warren $\mathrm{M}$, Matsuno $\mathrm{R}$, Tran $\mathrm{H}$, et al. Utility of Phox2b immunohistochemical stain in neural crest tumours and non-neural crest tumours in paediatric patients. 2018; 72(4):685.

44. Boettger T, Beetz N, Kostin S, et al. Acquisition of the contractile phenotype by murine arterial smooth muscle cells depends on the Mir143/145 gene cluster. Clin. Invest. 2009; 119(9):2634.

45. Lohmann K, Masuho I, Patil D N, et al. Novel GNB1 mutations disrupt assembly and function of G protein heterotrimers and cause global developmental delay in humans. Mol. Genet. 2017; 26(6):1078.

46. Sangodkar J, Perl A, Tohme R, et al. Activation of tumor suppressor protein PP2A inhibits KRASdriven tumor growth. Clin. Invest. 2017; 127(6):2081-2090. 
47. Pengo N, Agrotis A, Prak K, et al. A reversible phospho-switch mediated by ULK1 regulates the activity of autophagy protease ATG4B. Commun. 2017; 8(1):294.

48. Verhaegen $M$ E, Mangelberger $D$, Harms $P$ W, et al. Merkel cell polyomavirus small $T$ antigen initiates Merkel cell carcinoma-like tumor development in mice. Cancer Res. 2017; 77(12):3151.

49. Hamada N, Negishi Y, Mizuno M, et al. Role of a heterotrimeric G-protein, Gi2, in the corticogenesis: possible involvement in periventricular nodular heterotopia and intellectual disability. Neurochem. 2017; 140(1):82.

50. Supper V, Hartl I, Boulã"Gue C, et al. Dynamic Interaction- and Phospho-Proteomics Reveal Lck as a Major Signaling Hub of CD147 in T Cells. Immunol. 2017; 198(6):2468-2478.

51. Gutiérrez F J Q, Ángel Panizo, Tienza A, et al. Cytogenetic and immunohistochemical study of 42 pigmented microcystic chromophobe renal cell carcinoma (PMChRCC). Virchows Arch. 2018; 473(2):209-217.

52. Ferreira J, Duarte J, Diniz G B, et al. Litter size determines the number of melanin-concentrating hormone neurons in the medial preoptic area of Sprague Dawley lactating dams. Behav. 2017; 181:75-79.

53. Li H B, Tong J, Zhu S, et al. m6A mRNA methylation controls T cell homeostasis by targeting IL7/STAT5/SOCS pathway. 2017; 548(7667):338-342.

54. Johnson R W, Finger E C, Olcina M M, et al. Induction of LIFR confers a dormancy phenotype in breast cancer cells disseminated to the bone marrow. Cell Biol. 2017; 18(10):1078-1089.

55. Cameron D, Piccartgebhart M J, Gelber R D, et al. 11 years' follow-up of trastuzumab after adjuvant chemotherapy in HER2-positive early breast cancer: final analysis of the HERceptin Adjuvant (HERA) trial. 2017; 389(10075):1195-1205.

56. Pérez-Villegas E M, Negrete-Díaz J V, Porras-García M E, et al. Mutation of the HERC 1 Ubiquitin Ligase Impairs Associative Learning in the Lateral Amygdala. Neurobiol. 2018; 55(2):1157-1168.

57. Frias M A, James R W, Gerberwicht C, et al. Native and reconstituted HDL activate Stat3 in ventricular cardiomyocytes via ERK1/2: Role of sphingosine-1-phosphate. Res. 2017; 82(2):313.

58. Weng L, Zhang H, Li X, et al. Ampelopsin attenuates lipopolysaccharide-induced inflammatory response through the inhibition of the NF-KB and JAK2/STAT3 signaling pathways in microglia. Immunopharmacol. 2017; 44:1-8.

59. Kohanbash G, Carrera D A, Shrivastav S, et al. Isocitrate dehydrogenase mutations suppress STAT1 and CD8+ T cell accumulation in gliomas. J. Invest. 2017; 127(4):1425.

60. Chen K, Liu J, Liu S, et al. Methyltransferase SETD2-Mediated Methylation of STAT1 Is Critical for Interferon Antiviral Activity. Cell. 2017; 170(3):492.

61. Zhang H, Zhao Z, Pang X, et al. Genistein Protects Against Ox-LDL-Induced Inflammation Through MicroRNA-155/SOCS1-Mediated Repression of NF-KB Signaling Pathway in HUVECs. 2017; 40(4):1450-1459. 
62. Zheng $\mathrm{X}$, Huang $\mathrm{H}$, Liu J, et al. Propofol Attenuates Inflammatory Response in LPS-Activated Microglia by Regulating the miR-155/SOCS1 Pathway. 2018; 41(2):1-9.

63. Villarroyabeltri C, Guerra S, Sánchezmadrid F. ISGylation - a key to lock the cell gates for preventing the spread of threats. Cell Sci. 2017; 130(18):2961.

64. Baldanta S, Fernã n M, AcãN-Perez R, et al. ISG15 governs mitochondrial function in macrophages following vaccinia virus infection. PLoS Pathog. 2017; 13(10): e1006651.

65. Bianco C, Mohr I. Restriction of Human Cytomegalovirus Replication by ISG15, a Host Effector Regulated by cGAS-STING Double-Stranded-DNA Sensing. Virol. 2017; 91(9): e02483-16.

66. Chen D, Nan G, Bing X R, et al. ISG15 in Host Defense Against Candida albicans Infection in a Mouse Model of Fungal Keratitis. Ophthalmol. Vis. Sci. 2017; 58(7):2948-2958.

67. Choi Y J, Bowman J W, Jung J U. A Talented Duo: IFIT1 and IFIT3 Patrol Viral RNA Caps. 2018; 48(3):474-476.

68. Jiehua W, Min D, Yange C, et al. Elevated IFIT3 Contributes to Abnormal Overactive cGAS-STING Signaling in Human Systemic Lupus Erythematosus Monocytes. Arthritis Rheumatol. 2018; 70(12): 2036-2045.

\section{Figures}


A

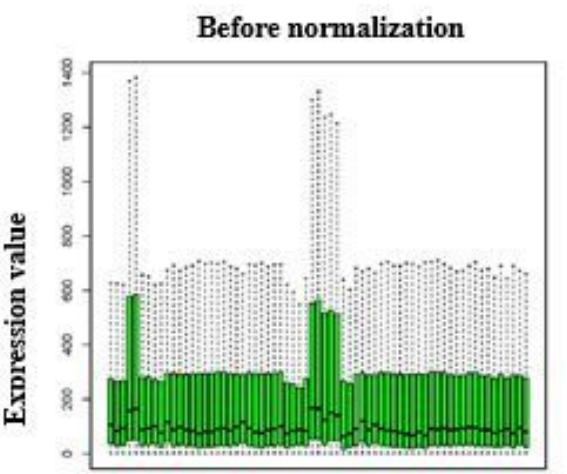

B

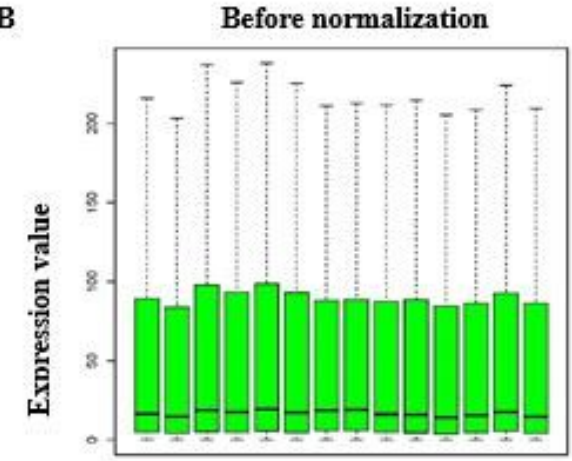

C

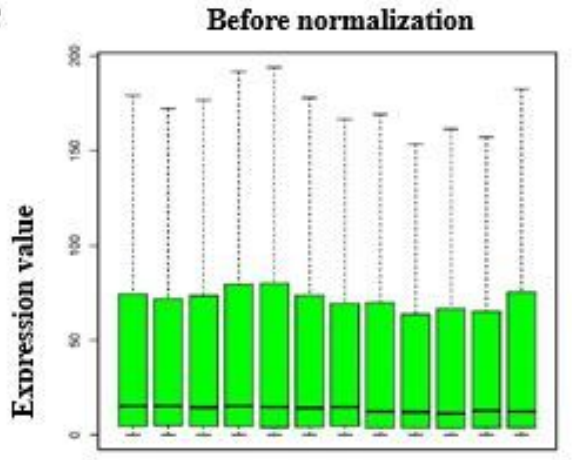

D

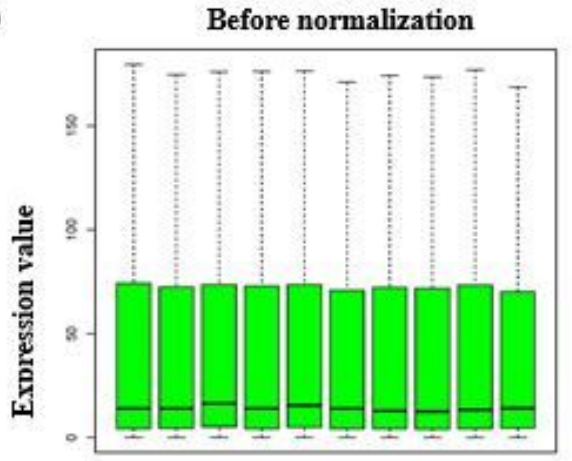

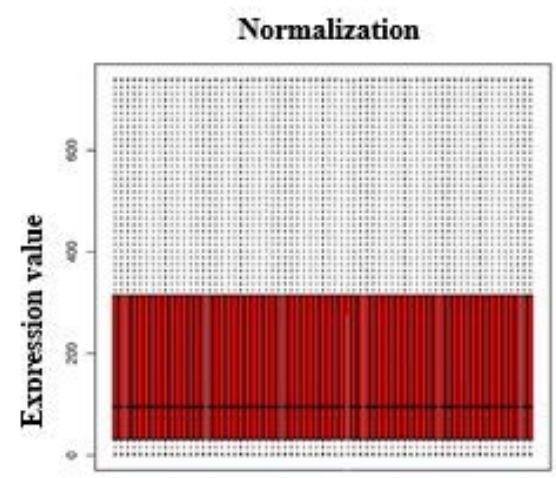

Normalization
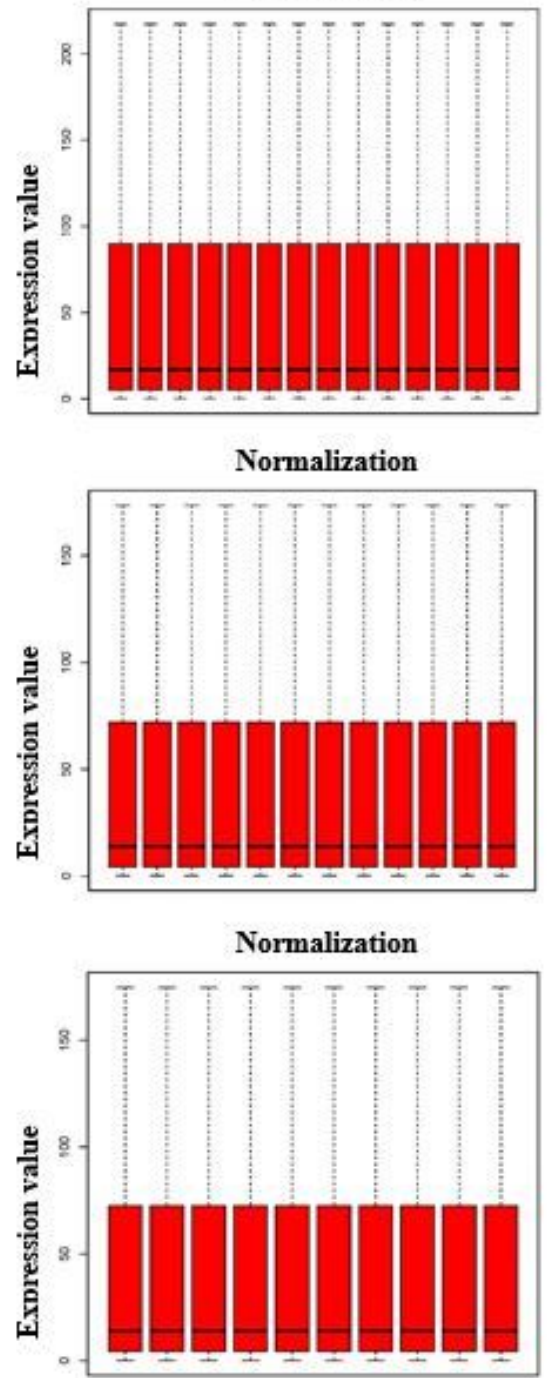

\section{Figure 1}

Standardization of gene expression. Notes: (A) The standardization of GDS4185 data, (B) the standardization of GDS4888 data, (C) the standardization of GDS4889 data, (D)GDS4890 data. The blue bar means the genetic information before normalization, and the red bar means the normalized genetic information. 
A

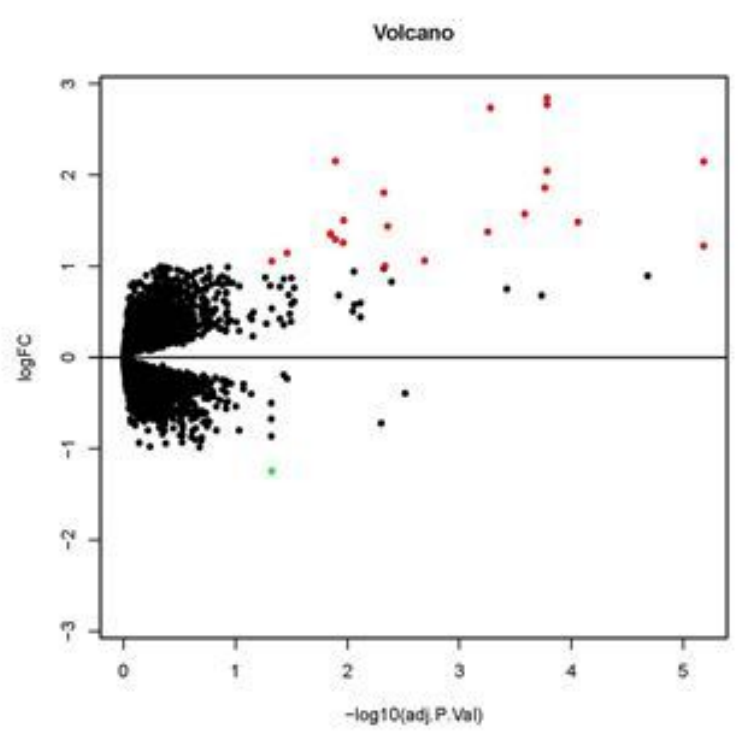

$\mathrm{C}$

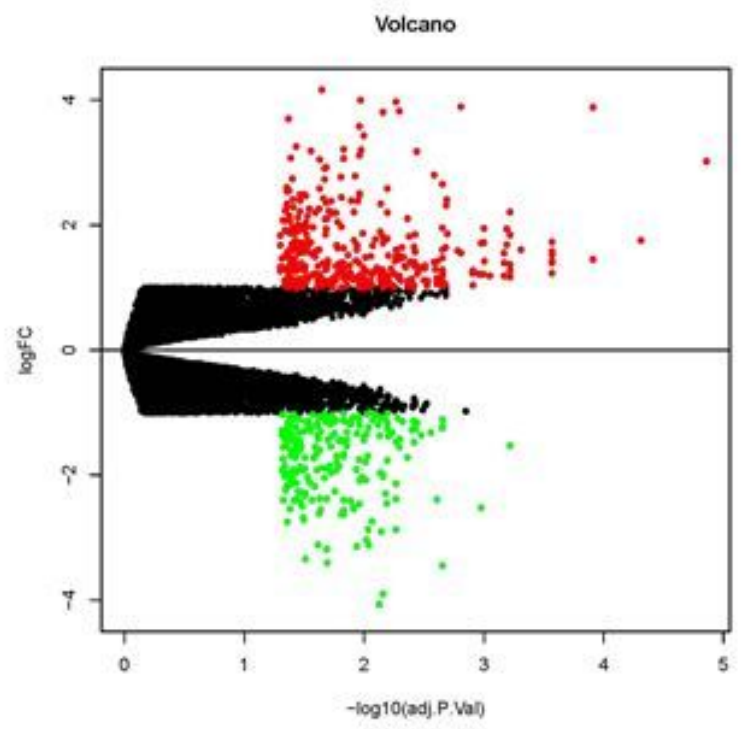

B

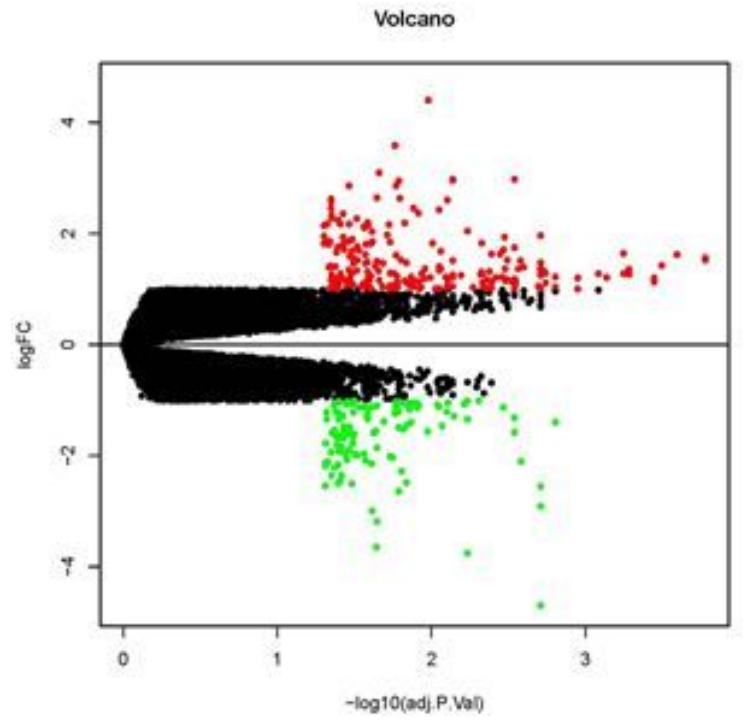

$\mathrm{D}$

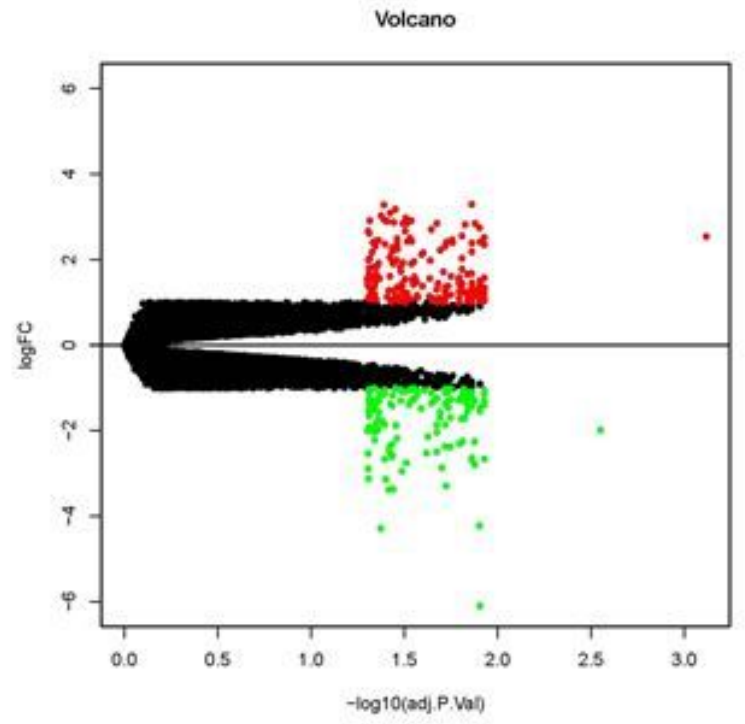

Figure 2

Differential expression of data between two sets of samples. Notes: (A) GDS4185 data, (B) GDS4188 data, (C) GDS4889 data, (D)GDS4890 data. The red points represent upregulated genes obtained based on |fold changel $>2.0$ and a corrected P-value of $<0.05$. The green points mean downregulation of the expression of genes obtained based on |fold change| $>2.0$ and a corrected P-value of $<0.05$. The black points mean genes with no significant difference. FC is the fold change. 
A

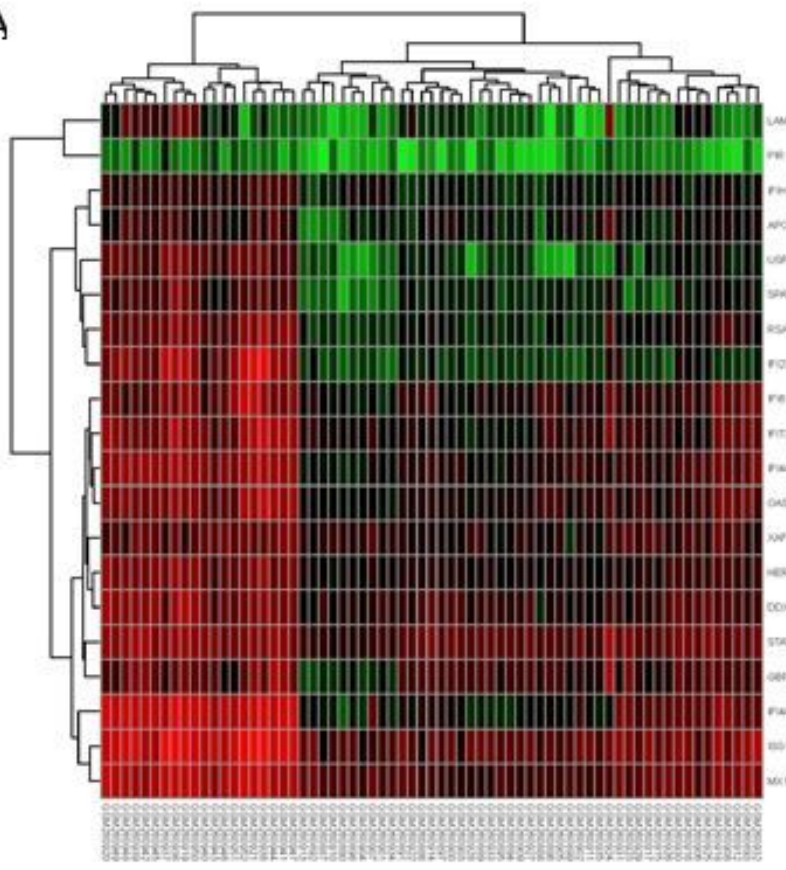

C

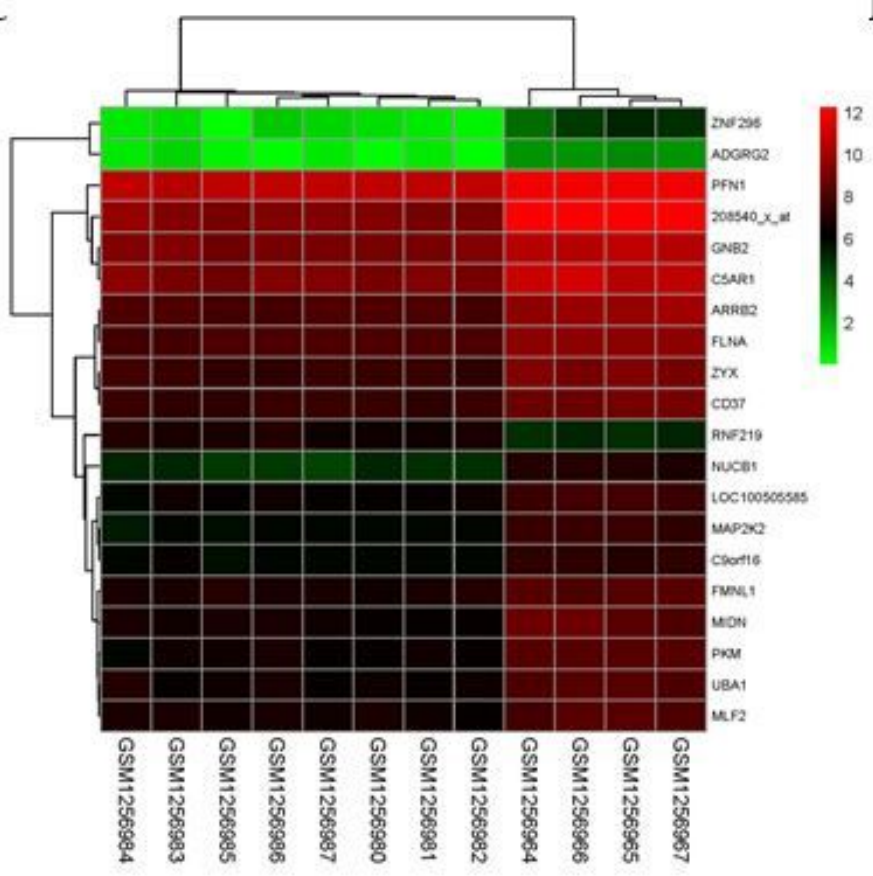

B

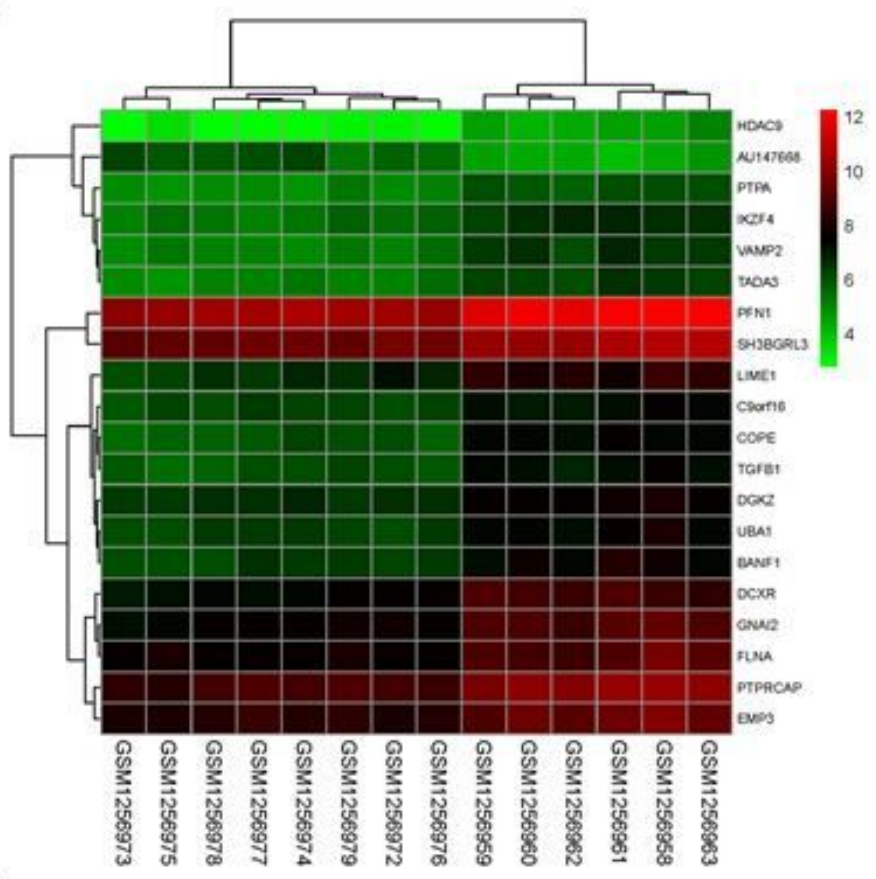

D

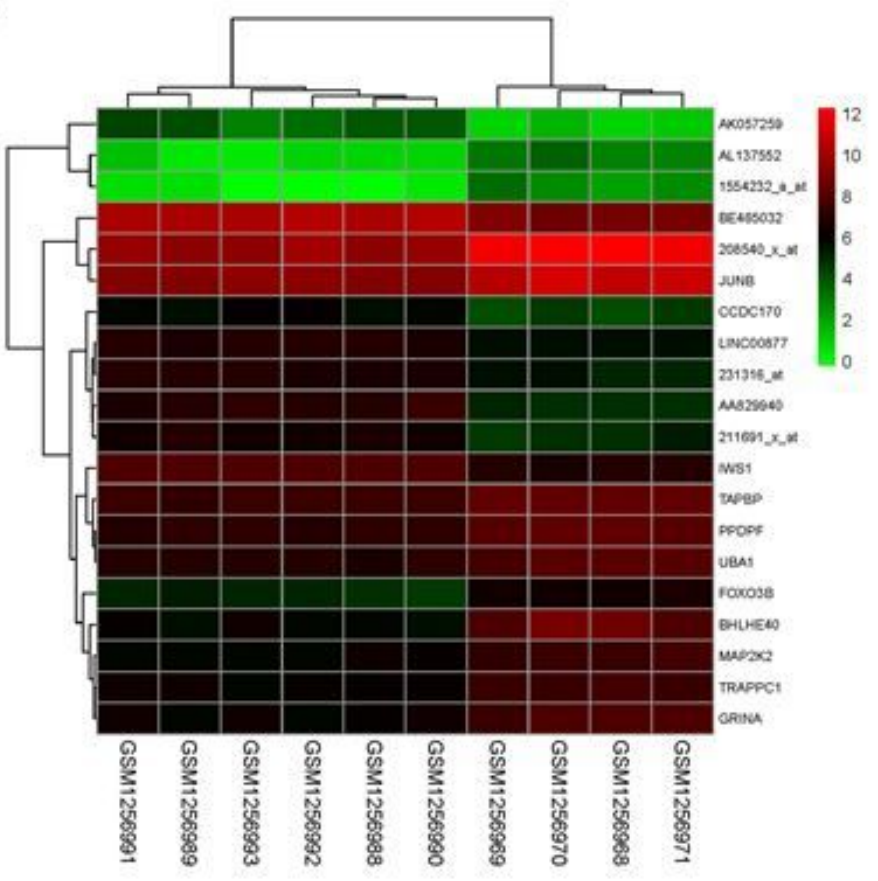

\section{Figure 3}

Hierarchical clustering heatmap of DEGs screened in standard by |fold change| $<2.0$ and a corrected Pvalue <0.05. Notes: (A) GDS4185 data, (B) GDS4188 data, (C) GDS4889 data, (D)GDS4890 data. Red means that the expression of genes is correspondingly upregulated, green means that the expression of genes is correspondingly downregulated, and black means no striking changes in gene expression; gray means that the signal intensity of genes was not high enough to be checked. Abbreviation: DEGs, differentially expressed genes. 


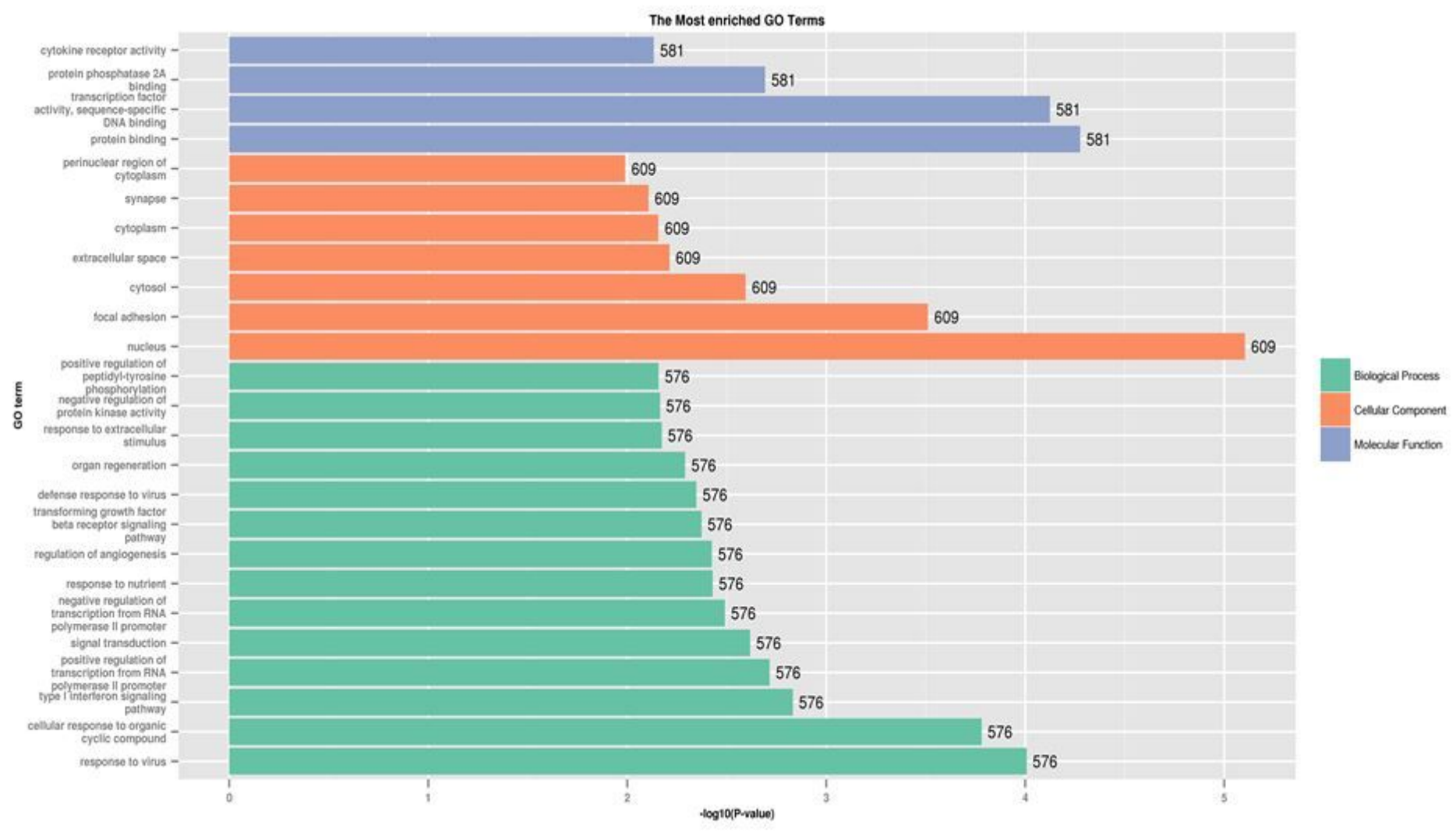

Figure 4

GO enrichment analysis of DEGs in SLE. Notes: GO analysis divided DEGs into three functional groups: biological processes, cell composition and molecular function. Abbreviations: DEGs, differentially expressed genes; GO, gene ontology. 


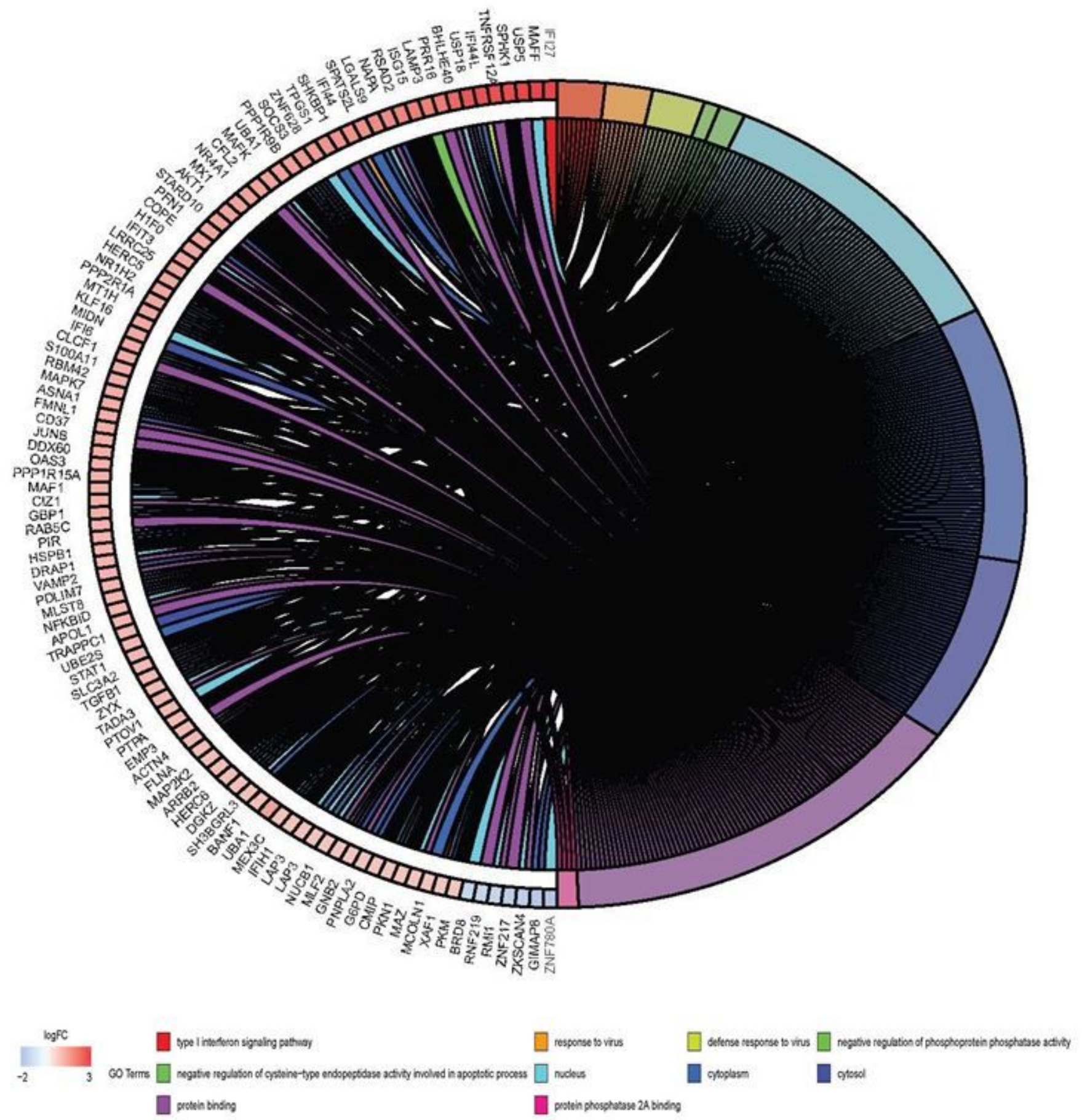

Figure 5

Distribution of DEGs in SLE for different GO-enriched functions. Abbreviations: DEGs, differentially expressed genes; GO, gene ontology. 


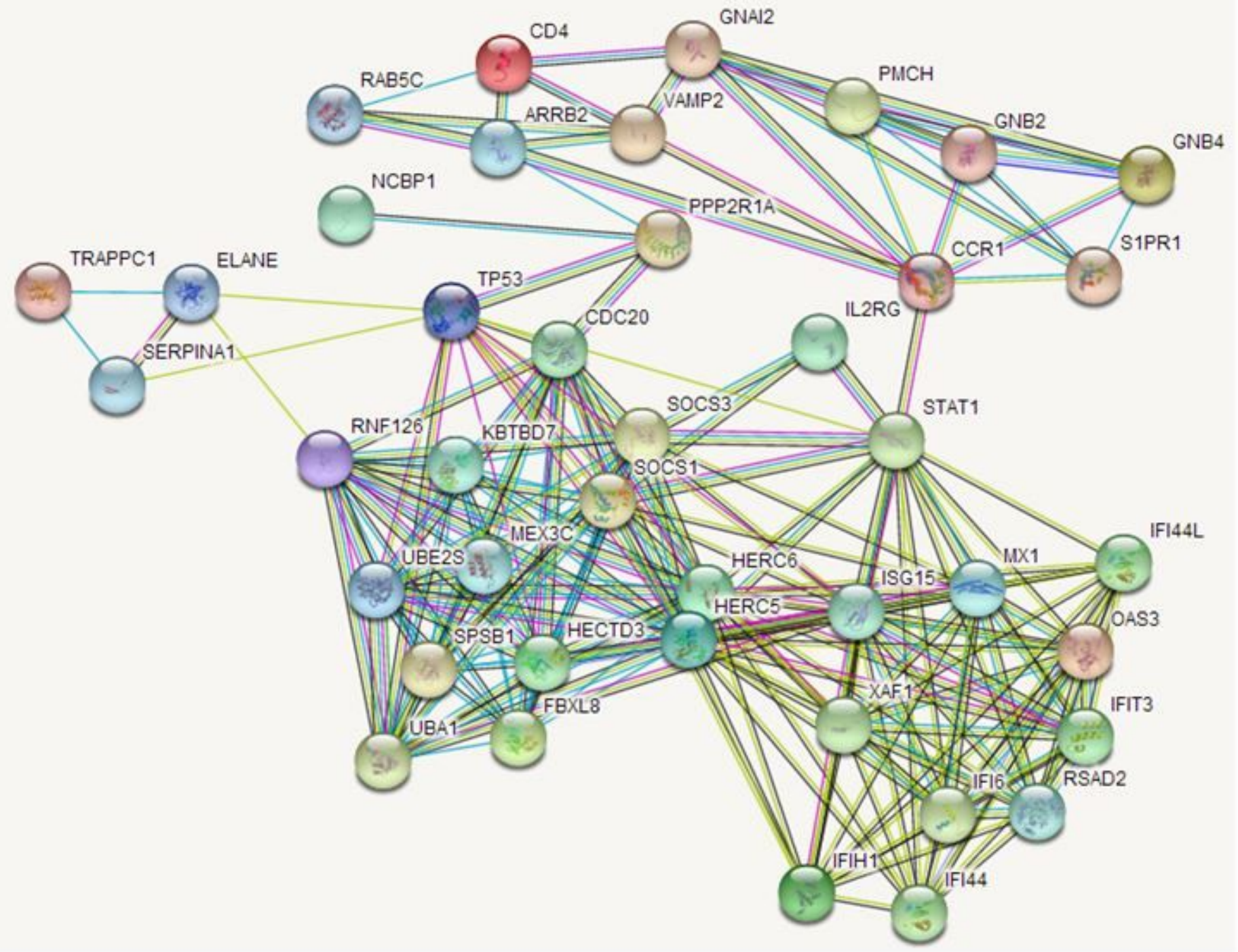

Figure 6

PPI network. Notes: Circles represent genes, lines represent the interaction of proteins between genes, and the results within the circle represent the structure of proteins. Line color represents evidence of the interaction between the proteins. Abbreviation: PPI, protein-protein interaction. 